DRD DISCUSSION PAPER

Report No. DRD256

GOVERRMENT DEFICITS, PRIVATE INVESTMENT AND THE CURRENT ACCOUNT: AN INTERTEMPORAL DISEQUILIBRIUM ANALYSIS

by

Sweder van Wijnbergen

March 1987

Development Research Department

Economics and Research Stat

World Bank

The World Bank does not accept responsibility for the views expressed herein which are those of the author(s) and should not be atcributed to the world Bank or to its affiliated organizations. The findings, interpretations, and conclusions are the results of research supported by the Bank; they do not recessarily represent official policy of the Bank. The designations employed, the presentation of material, and any maps used in this document are solely for the convenience of the reader and do not imply the expression of any opinion whassever on the part of the World Bank or its affiliates concerning the legal status of any councry, territory, city, area, or of its authorities, or concening the delimitations of its boundaries, or national affiliation. 


\title{
GOVERNMENT DEFICITS, PEIVATE INVESTMENT AND THE CURRENT ACCOUNT: AN INTERTEMPORAI DISEQUILIBRIUM ANALYSIS
}

\author{
Sweder van Wijnbergen \\ World Bank \\ CEPR and NBER
}
First Draft June 1984
January 1987
Revised March 1987

I am indebted to John Cuddington for helpful comments. The World Bank does not accept responsibility for the views expressed herein which are those of the author. 
We use a model with full intertemporal optimization and Fischer-Gray type short run real wage rigidities to demonstrate the effects of deficit spending in different employment regimes. We allow for upward price flexibility, although prices, once set at the beginning of the period, will be rigid downward until the beginning of the next period. We show that under Keynesian unemployment (conditional on a plausible assumption about public and private sector discount rates) deficit spending reduces unemployment, improves the future terms of trade and therefore leads to an increase in private investment (crowding in) and to a deterioration of the Current Account. Under classical unemployment, goods markets clear but unemployment persists because of contract based real wage rigidity. Fiscal expansion then goes partly into prices (terms of trade improvement) and only partly into quantities. The latter occurs to the extent that contract based real consumption wage rigidity, coupled with a terms of trade improvement, allows a lower real product wage. A temporary increase in government expenditure in classical unemployment leads to a bigger terms of trade improvement today than tomorrow, so both income and substitution effects lead to a current account improvement. The cost of capital increases more than the value of future output and investment falls. This also improves the first period current account. The direct impact of increased first period government expenditure may offset these surprising positive effects on the first period current account.

Finally we show that, the more open the economy is, the larger is the output response and the smaller the price response to a fiscal expansion in the presence of classical unemployment. This contrasts with the Keynesian 
unemployment regime, where a higher import component in expenditure leads to more dissipation of effective demand and smaller output effects. 
Table of Contents

Page No

I. Introduction

1

II An Intertemporal Contract-Based INisequilibrium Model

3

III. Fiscal Policy Under Keynesian Unemployment

IV. Fiscal Policy Under Classical Unemployment

V. Conclusions

30

Appendix 


\section{Introduction}

The emergence of substantial government deficits in the late seventies and early eighties has brought government deficits and their effects on the economy back to the foreground of policy debate. Large deficits in the US played a part in the remarkably fast recovery in 1983 and 1984, but, so many observers claim, at the cost of high real interest rates and external deficits on current account. Investment has recovered strongly however, high real interest rates notwithstanding. In Western Europe large deficits have not prevented increasing unemployment, while private investment has remained extremely weak. An extreme example is Holland where large government deficits have gone together with ever increasing unemployment, collapsing private investment and, surprisingly enough, substantial current account surpluses. The existing literature does not give as too much guidance in explaining these developments. Two strands can be distinguished. The first goes back to Keynes (1936), Hicks (1939) and Haavelmo (1945). The focus here is exclusively on short-run aggregate demand effects; a traditional set up of static consumption functions and demand-driven supply is used. Disequilibrium in labor and goods markets is not explicitly incorporated, while the intertemporal aspects (e.g. less taxes today means more taxes tomorrow) are typically ignored.

The other strand in the literature focuses almost exclusively on these intertemporal aspects. One of the best known examples of this part of the 1iterature is Barro (1974). In contrast to the earlier 1iterature, these authors base private behavior on explicit intertemporal optimization. That allows a satisfactory analysis of changes in the intertemporal pattern of taxes; an ambitious open economy extension of this literature is Frenkel and Razin (1985a). However, their use of full employment, market clearing models 
precludes a meaningful discussion of the stabilization aspects of fiscal policy.

In this paper we will attempt to bring the two strands together. We analyze fiscal policy in the context of a model with intertemporal optimization underlying private behavior. But we also explicitly incorporate the possibility of (short-run) labor and goods market disequilibrium caused by Fischer (1977)-Gray (1978) type contract-based real wage rigidities and within-period downward price inflexibility. Prices are however assumed to be flexible upward, in a departure from the standard disequilibrium literature. There is both theoretical and empirical support for such an asymmetry. We discuss this further in section II. In another departure from the standard disequilibrium 1iterature, but in line with modern contract theory, we incorporate temporary real consumption wage rigidity, rather than permanent, nominal wage rigidity.

This potential for labor and goods market disequilibrium allows us to address stabilization aspects of fiscal policy (impact on aggregate output and employment). Cuddington and Vinals (1986a,b) also incorporate temporary disequilibrium in an intertemporal optimization model in their discussion of fiscal policy. They focus on monetary aspects and moreover maintain complete within-period nominal-wage-price rigidity, as opposed to our assumptions of asymmetric price adjustment (flexible upwards but rigid downward) and contract based real consumption-wage rigidity. Moreover, they ignore investment and have to rely on very restrictive functional forms, thereby eliminating many of the intertemporal relative price effects that play an important role in our analysis. Other disequilibrium models incorporating rational optimizing saving and investment behavior can be found in Bruno (1982), Neary and Stig1itz (1983) and van Wijnbergen (1985). 
In Section II the basic model is presented. We use a two-period model where wages and prices are set at the beginning of each period using all available information. This is done in such a way that all markets will be in equilibrium if no unanticipated events occur after the contracts have been concluded. If such events do occur, there may be disequilibrium in labor and goods markets. The implications of that are analyzed in the tradition of Barro-Grossman (1976), Benassy (1975) and Malinvaud (1977), while maintaining an explicit intertemporal optimization framework and allowing for upward price flexibility, contrary to much of the existing disequilibrium literature. Fiscal policy effects under Keynesian unemployment are analyzed in Section III, while Section IV looks at the case of classical unem. oyment. Section $V$ concludes.

\section{An Intertemporal, Contract-Based Disequilibrium Model}

A. Consider a two-period, two-commodity world. Period one corresponds to the "short run". In this period, the capital stock cannot be adjusted and wage-price rigidities may exist. A11 shocks taking place in this period are unanticipated. In the second period, the "long run", wages, prices and the capital stock can adjust. An artificial but innocuous consequence of the twoperiod structure is that no investment takes place in the second period. Another implication of the two-period structure is that all debts carried over from period one need to be paid off in period two.

The economy specializes completely in the production of good 1 while foreigners specialize in the production of good 2. Firms use the beginning of period capital stock and labor as factors of production, and determine output based on the size of the capital stock and the level of the real product wage. This process can be described by using a revenue function (a good 
exposition of this and other duality tools can be found in Dixit and Norman $(1980)):$

$$
\begin{aligned}
R & =R(P ; K, L) \\
& =P X(K, L)
\end{aligned}
$$

where $P$ is the price of home goods in period 1. Capital letters indicate first period variables, and lower case symbols second-period variables. Foreign goods are chosen as numeraire, so we can interpret $P$ and $p$ as the first and second period terms of trade. Labor demand is given by the requirement that the marginal value product equals the wage:

$$
R_{L}=W
$$

Inverting (2) yields a labor demand function $\mathrm{L}=\mathrm{L}(\mathrm{W} / \mathrm{P}, \mathrm{K})$. If we insert that back into (1) we get:

$$
R=P X(K, L(W / P))
$$

$$
=R(P, W / P)
$$

with output supply equal to

$$
\begin{aligned}
X & =\frac{\partial R}{\partial P}=R_{P} \\
& =X(K, L(W / P))
\end{aligned}
$$


We assume full employment in the second period (the "long run"), for reasons explained in the beginning of section II.B. As a consequence, second period output $\mathbf{x}$ depends on the second period capital stock only

$$
\begin{aligned}
r & =r(p, k) \\
& =p x(k)
\end{aligned}
$$

and

$$
x=\frac{\partial r}{\partial p}
$$

We ignore depreciation, so $\mathrm{k}=\mathrm{K}+\mathrm{I}$ where $\mathrm{I}$ is first period investment. Investment is determined by value maximizing firms, equalizing the discounted value of future marginal revenue to the production cost of capital:

$$
\delta p \frac{\partial x}{\partial k}(K+I)=p
$$

We assume for simplicity that investment only requires domestic goods as input. $\delta$ is the discount factor $1 /\left(1+\rho^{*}\right)$ with $\rho^{*}$ the world rate of interest. We assume that the economy is too small to influence the world interest rate $\rho^{*}$.

Equation (7a) yields an investment demand function:

$$
I=I(\delta \mathrm{p} / \mathrm{P}), I^{\prime}=-\mathrm{x}_{\mathrm{k}} /\left(\delta \mathrm{px}_{\mathrm{kk}} / \mathrm{P}\right)>0
$$


Equation (7b) also incorporates our assumption of perfect foresight.

We make the same assumption for consumer behavior, to which we turn now. We make no distinction between consumption patterns of wage earners and profit recipients. However, we assume that profits are paid out in the period in which they are earned, contrary to Malinvaud (1977) or Neary (1980). An expenditure function describes consumer behavior. The expenditure function gives the minimum discounted value of expenditure needed to reach utility level U given prices today and tomorrow (again see Dixit and Norman (1980) for an exposition of expenditure functions):

$$
E=E(\pi(P, 1), \delta \pi(p, 1), U)
$$

where II and $\pi$ are unit expenditure functions and the exact aggregate price indices corresponding to the utility structure $U$. $1 /$ By the properties of expenditure functicns we know that domestic consumer demand for home goods, $C_{D}$ ( $c_{D}$ for the second period), equals the derivative of $E$ with respect to the corresponding price:

$$
C_{D}=E_{P}, C_{D}=E_{p}
$$

Also II and $\pi$ are aggregate price indices, so we can define real expenditure in each period:

1/ We assume U to be Weakly Identically Homothetically Separable, which allows us to write $\mathrm{E}$ as a function of $\mathrm{U}$ and the within-period unit expenditure functions $\pi$ and $\pi$. See Razin and Svensson (1983) and van Wi jnbergen (1984) for a detailed discussion. 


$$
A=E_{\Pi}, a=E_{\pi}
$$

$I$ and $\pi$ are unit expenditure functions, so $\Pi_{P}=C_{D} / A$ and $\pi_{p}=c_{D} / a$.

Furthermore we can derive similar expressions for foreigners, for whom we will use starred variables $\left(E^{*}, C_{D}^{*}, A^{*}\right.$ etc. $)$.

Expenditure needs to satisfy the private sector intertemporal budget constraint:

$$
R+\delta r-P I-\tilde{T}=E, R^{*}+\delta r^{*}=E^{*}
$$

Government and investment in the foreign country are ignored. $\tilde{T}$ equals the discounted value of srrent and future taxes: $\tilde{T}=T+\delta t$ with obvious definitions of $T$ and $t$. Under the assumption of identical government and private discount rates, $\tilde{T}=P G+\delta p g$ via the government budget constraint. (More on this in Section II.E).

First period goods market equilibrium requires:

$$
\begin{aligned}
R_{P} & =C_{D}+C_{D}^{*}+I+G \\
& =E_{P}+E_{P}^{*}+I(\delta p / P)+G
\end{aligned}
$$

where $G$ is first period government expenditure. Similarly, for period 2:

$$
r_{p}=E_{p}+E_{p}^{*}+g
$$


$(12 a, b)$ embed the assumption that both government and investment expenditure fall entirely on domestic goods.

We assume a fixed labor supply $\overline{\mathrm{L}}$, so the labor market equilibrium condition is given by:

$$
\overline{\mathrm{L}}=L(W / P)
$$

Equations ( 8 ) and (11) yield private welfare at home, U, and abroad, $U^{*}$, as a function of $P, P, T$ and $t$ :

$$
U=U(P, P, T, t), U^{*}=U^{*}(P, p)
$$

or, in differentiated form and using $(12 a, b)$ to substitute out expressions like $r_{P}-E_{P}-I-g$ etc.:

$$
E_{P}^{*} d P+E_{p}^{*} \delta d p-d T-\delta d t=E_{u} d U
$$

and

$$
-E_{P}^{*} d P-E_{p}^{*} \delta d P=E_{u}^{*} d U^{*} .
$$

$(14 b, c)$ are evaluated around $G=g=0$ to avoid irrelevant valuation effects on government expenditure. (11a, b), (12) and (14) constitute an equilibrium version of the model, with variables $P, P, W / P, U$ and $U^{*}$. We will first give a diagrammatic representation of this equilibrium version, because that will facilitat: the introduction of the consequences of first period disequilibrium. 
Inserting (14) in (12a) to substitute out $U$ and $U^{*}$ gives us a locus describing goods market equilibrium in period 1, represented by GM1 in fig. 1:

$$
\left.\frac{\mathrm{d}(W / \mathrm{P})}{\mathrm{dP}}\right|_{\mathrm{GMI}}=\frac{\Sigma_{\mathrm{PP}}-I^{\prime} \delta \mathrm{p} / \mathrm{P}^{2}}{\mathrm{X}_{\mathrm{L}} \mathrm{L}^{\prime}}
$$

with $\Sigma_{P P}=E_{P P}+E_{P P}^{*}+\left(C_{D E}-C_{D E}^{*}\right) E_{p}^{*}$, the world substitution matrix plus income effects of an increase in $\mathrm{P} . \quad \Sigma_{\mathrm{PP}}<0$ for normal goods. $C_{D E}$ is ("our") marginal propensity to spend on our first period goods, $\mathrm{E}_{\mathrm{PU}} \mathrm{E}_{\mathrm{U}}^{-1} \cdot \mathrm{C}_{\mathrm{DE}}^{*}$ is the foreign marginal propensity to spend on our first period goods, $E_{\mathrm{PU}}^{*} \mathrm{E}_{\mathrm{U}}^{*-1}$. GMI is upward sloping: a higher (relative) price of our goods reduces world demand for our goods, leading to excess supply; a higher real product wage however will reduce aggregate supply (cf. fig. 1).

Labor market equilibrium is represented by (13), a horizontal 1 ine in the $W / \mathrm{P}-\mathrm{P}$ plane:

$$
\left.\frac{\mathrm{d} W / \mathrm{P}}{\mathrm{dP}}\right|_{\mathrm{LL}}=0
$$

Since labor is the only variable factor in this model, there is only one market clearing real product wage.

The second period goods market equilibrium locus GM2 slopes upward (cf. fig. 1 and keep in mind that $p$ increases from 0 downwards):

$$
\left.\frac{\mathrm{dp}}{\mathrm{dP}}\right|_{\mathrm{GM} 2}=-\frac{\left(\Sigma_{\mathrm{pP}}+r_{p k} I^{\prime} \delta \mathrm{p} / \mathrm{P}^{2}\right)}{\left(\Sigma_{\mathrm{pp}}-\mathrm{r}_{\mathrm{pk}} I^{\prime} \delta / \mathrm{P}\right)}>0
$$

where $\Sigma_{\mathrm{pP}}$ and $\Sigma_{\mathrm{pp}}$ are the relevant elements of the world substitution matrix plus income effects $\left(\Sigma_{p P}=E_{p P}+E_{p P}+\left(c_{D E}-c_{D E}^{*}\right) E_{P}^{*}\right.$ etc $) ; \Sigma_{p P}>0$ and $\Sigma_{p p}<0$ with sufficient symmetry. $\left(C_{D E}\right.$ not too much larger than $\left.C_{D E}^{*}\right)$ 


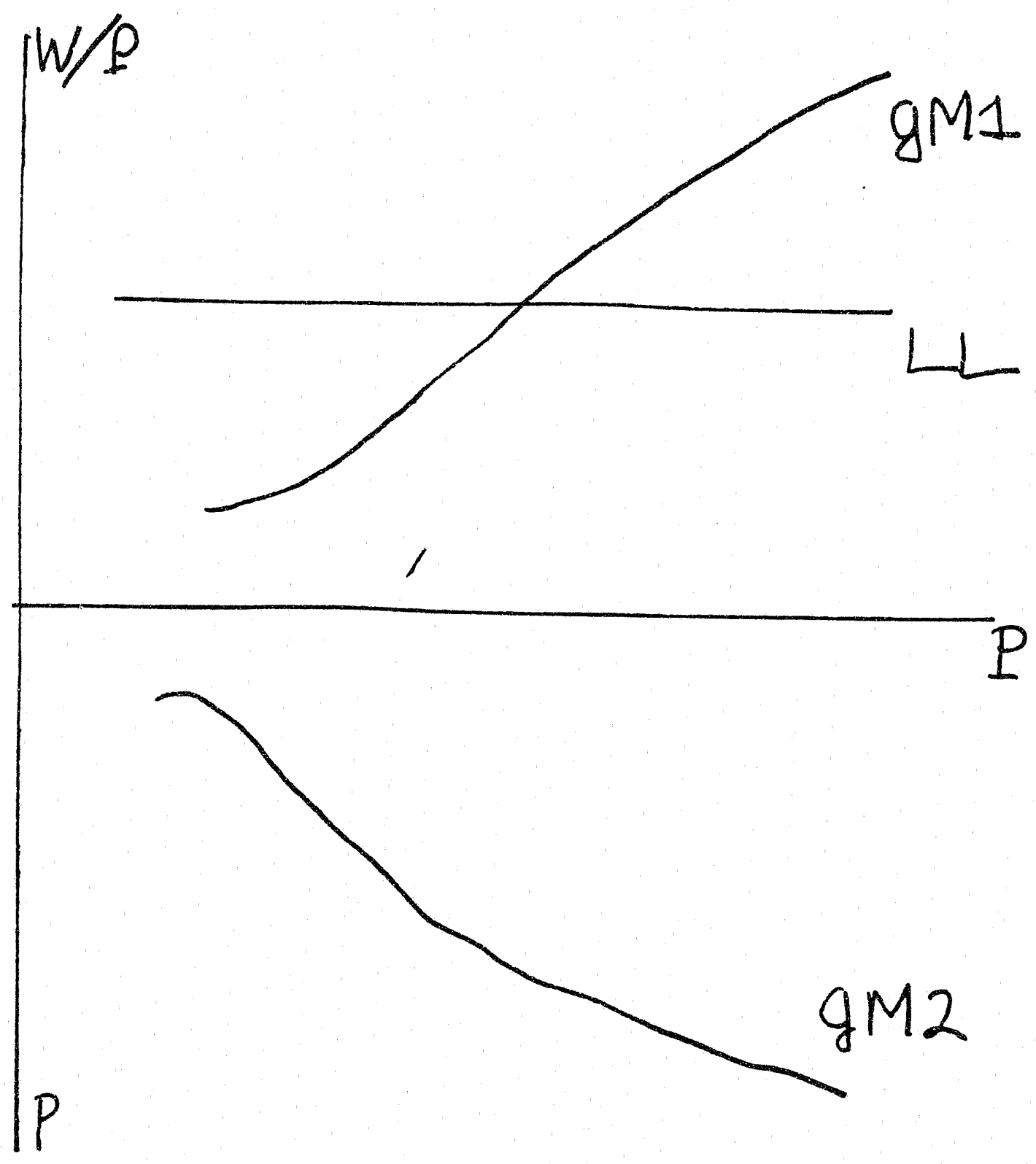

Figure 1: Diagrammatic Representation of the Market Clearing Model 
Two channels link $\mathrm{p}$ and $\mathrm{P}$ via the second period goods market. The first runs through $\delta \mathrm{p} / \mathrm{P}$. For given $\mathrm{p}$, a higher $\mathrm{P}$ raises the production cost of capital which will lead to lower investment. That in turn reduces aggregate supply in period two, leading to upward pressure on p. The second channel also leads to a positive relation, through substitution effects in consumption. Higher prices today for given $p$ will decrease the consumption discount factor $\delta \pi(p, 1) / \pi(P, 1)=1 /(1+C R I)$. CRI is the consumption rate of interest (cf. Little and Mirrees (1974)). This will lead to a shift of expenditure towards the future because of pure substitution effects, some of which will fall on period 2 home goods. This also puts upward pressure on their relative price $p$, like the effect via the first channel, so there is an unambiguously positive link between $\mathrm{p}$ and $\mathrm{P}$ along GR2 (cf. fig. 1 ).

Before we introduce disequilibrium, one final point: the diagram in Fig. 1 involves a fudge, necessary to allow diagrammatic representation. The same channels linking $\mathrm{p}$ and $\mathrm{P}$ via period two goods market clearing also work backwards: future prices do influence first period goods markets, via the value of capital in period 2 (and so via first period investment), and via the impact of the CRI on private savings. This of course implies that we cannot really represent GM1 in $\mathrm{W} / \mathrm{P}-\mathrm{P}$ space. The algebraic derivation of all results incorporates this extra link, but we will ignore it in the diagrammatic representation. $1 /$ It is left to the interested reader to demonstrate than an increase in $\mathrm{p}$ shifts $\mathrm{GM} 1$ to the right.

1/ All algebraic derivations are spelled out in detail in. the mathematical appendix. 


\section{B. Consequences of wage-price rigidity}

Consider now the introduction of disequilibrium. Assume that, at the beginning of the period, wage contracts are concluded indexing real wages in terms of the cost of living, and relative prices are announced. All this is done using all information available at that time, and in such a way that labor and goods markets will clear if no unanticipated shocks will occur during the period. We will not consider period 2 shocks unanticipated at the beginning of period 2, so in that period (the "long run") the economy will a1ways be in Walrasian equilibrium. Green and Laffont (1981) in their discussion of similar pricing behavior, call this "rational anticipatory pricing."

Temporary real wage rigidity of course has a firm basis in modern contract theory. The foundation for price rigidity on the other hand, is less solid. The disequilibrium literature has always assumed complete price rigidity. Although there is empirical evidence that relative prices move gradually rather than instantaneously in response to goods market disequilibrium (see especially Alogoskoufis and Pissarides (1983)), there are two major problems. First of all it of course does not make sense in any but the short run to assume price rigidity. We acknowledge this by assuming complete price flexibility in the second period ("long-run").

The second problem is that the implication of nationwide goods market rationing in excess demand situations seems clearly counterfactual, although it may take place on a lower level of aggregation. Moreover there is theoretical support for asymmetric price adjustment, with prices more flexible upwards than downwards (Reagan ((1983)), Reagan and Weitzman (1983)). We therefore adopt an extreme form of such asymmetric behavior: we assume complete price flexibility in excess demand situations (upward flexibility), 
but within-period downward rigidity when unanticipated shocks cause excess supply of goods.

Some modifications to the model are necessary because of potential disequilibrium and the associated spillover effects. The expression for goods market equilibrium under excess supply of labor changes, although firms are not constrained in this situation. But consumers' intertemporal budget constraint is affected because now employment and therefore income is variable and will depend on the real product wage. Substituting out $U$ via the modified budget constraint gives:

$$
\left.\frac{\partial W / P}{\partial P}\right|_{G M 1}=\frac{\Sigma_{P P}-I^{\prime} \delta p / P^{2}}{\left(1-C_{D E} P\right) X_{L} L^{\prime}}>0
$$

Comparison of (18) with (15) shows that this segment of GMI will still be upward sloping, and in fact will be steeper than in the equilibrium version, because of the term $-C_{D E} X_{L} L^{\prime}$ in the denominator. This is because higher wages will now not only cut aggregate supply, but also demand for home goods through their negative impact on employment and therefore total income. This means that a smaller price increase is needed to rebalance goods markets after a given increase in real product wages $W / P$ : GMI is steeper (cf. fig. 2).

The loci describing goods market equilibrium under excess demand for labor, and labor market equilibrium under excess supply of goods, collapse into one locus in this type of model without inventories and with complete specialization of production. This eliminates the so-called "underconsumptionist" regime.

In the area above LL and to the left of $G M 1$, prizes and wages are such that labor is in excess supply and domestic goods in excess demand. 


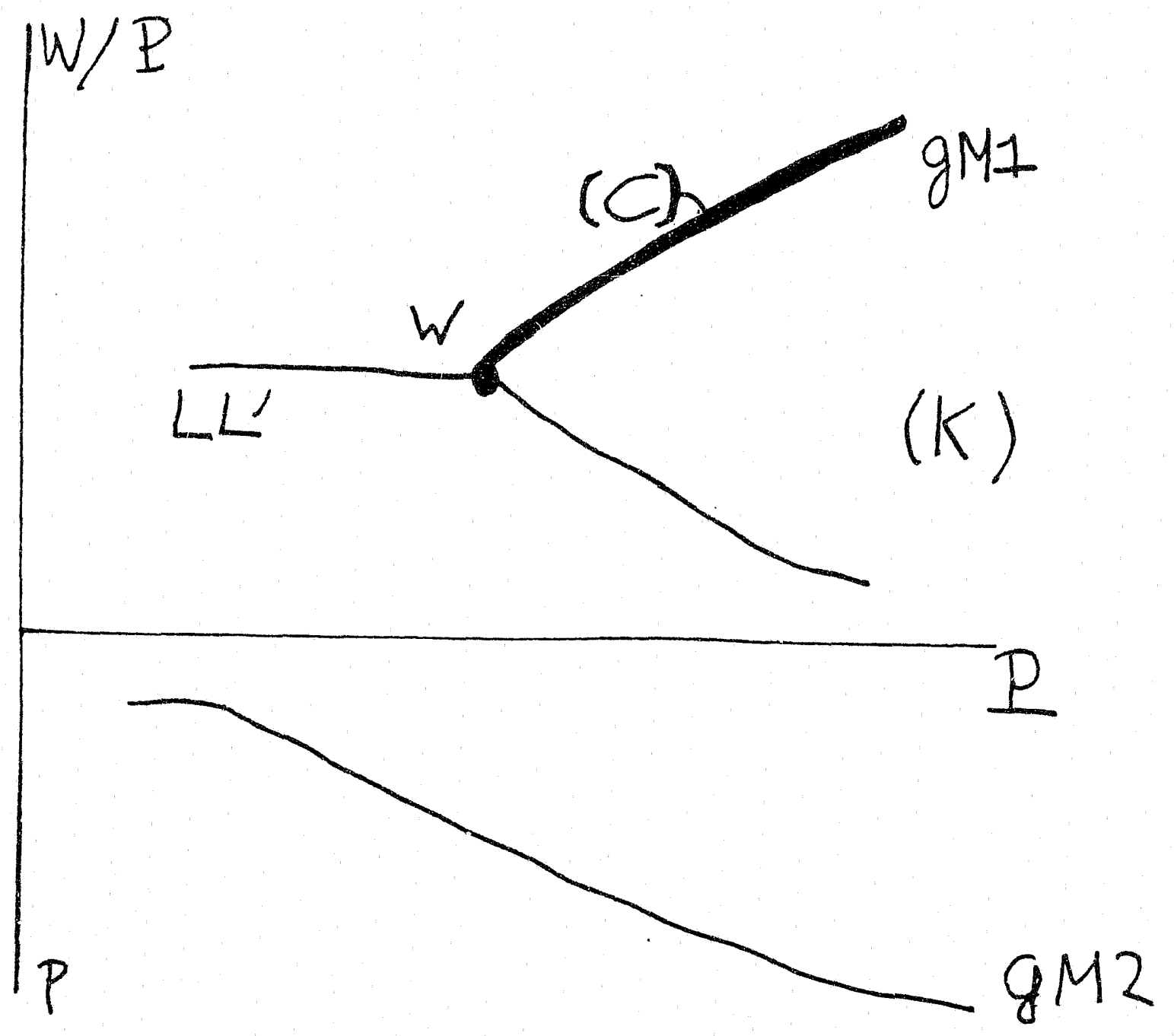

Figure 2: First Period Disequilibrium Regions and Second Period Goods Market Clearing Locus 
However, because of our assumption of upward price flexibility, the economy will never be in that region: prices will increase until the economy is on the GMI locus, with goods markets in equilibrium, but real wages too high for labor market equilibrium.

Accordingly, one unemployment regime is the $\mathrm{K}$-region to the right of GM1, with Keynesian unemployment: here output is demand-determined because prices are set too high for all the supply to be absorbed. The second regime is along the GMI locus from the Walrasian equilibrium point W upwards, with the goods market in equilibrium but real wages too high for labor market clearing. We will call this regime classical unemployment, although it is different from what is commonly called classical unemployment in the disequilibrium literature: our "C region" is not characterized by goods market rationing. $1 /$

The GM2 locus will now change and will depend on the regime prevailing in period 1. However, it is still sloped as in fig. 1 in all three cases. So we can use the diagram in fig. 2 as long as no regime switches are considered.

\section{The Keynesian Unemployment Regime.}

The behavioral equations of course change discontinuously across regimes. Consider first the K-region. First period output in that region is demand determined:

$$
X=E_{P}+E_{P}^{*}+I+G
$$

1/ The C-region as defined here corresponds to the boundary between the Keynesian and classical regions in more conventional disequilibrium models. 
where $R_{P}>X$. Second period goods market equilibrium is similar to $12 b$ :

$$
r_{p}(K+I)=E_{p}^{*}+E_{p}+g
$$

but the domestic private intertemporal budget constraint is different:

$$
\mathrm{PX}+\delta \mathbf{r}-\mathrm{PI}-\tilde{\mathrm{T}}=\mathrm{E}
$$

where $\mathrm{PX}$ replaces $\mathrm{R}$ (note that $\mathrm{R}>\mathrm{PX}$ in this regime!). The foreign budget constraint remains unchanged.

D. The Classical Unemployment Regime.

Under classical unemployment, first period output is supply determined and prices (P) will adjust until goods markets clear. Accordingly the following goods market clearing condition holds:

$$
R_{P}=E_{P}+E_{P}^{*}+I+G
$$

Second period goods market equilibrium, as before, is represented by:

$$
r_{p}(p, K+I)=E_{p}+E_{p}^{*}+g
$$

The difference from the equilibrium model of Section 2.2 lies in the labor market: wages are fixed in terms of the cost of 1 iving, at a level that would have led to labor market clearing if no unanticipated shock had occurred 
after the conclusion of wage contracts. We have an exact measure of the first period cost of living via our unit expenditure function II, so:

$\mathrm{W} / \mathrm{II}=\omega$

Finally the domestic private intertemporal budget constraint:

$$
R(P, W / P)+\delta r(P, K+I)-\tilde{T}-P I=E
$$

Employment in this regime is of course demand determined: by inverting equation (3) we get:

$$
L=L(W / P)
$$

Note that prices are flexible upwards while there is real consumption wage rigidity. Accordingly the real product wage $W / P$ is not rigid.

The model applying to the Repressed Inflation regime is left to the interested reader to explore since we will not be concerned with that regime in this paper.

E. The Government Budget Constraint.

Before turning to the analysis of fiscal policy, a discussion of the government budget constraint is in order. The benchmark case involves equal discount rates for public and private sector. This implies

$$
\mathrm{PG}+\delta \mathrm{pg}=\mathrm{T}+\delta \mathrm{t}(=\tilde{\mathrm{T}})
$$


There are however reasons to expect that the appropriate rate for the public sector to discount future income is different from the private discount rate. A straightforward argument is that governments can borrow at more favorable terms in international capital markets than the private sector. A different argument has been presented by Blanchard (1985) who points out that uncertain lifetime coupled with absence of private bequest motive will lead to a higher private discount rate. (cf. Frenkel and Razin (1985b) for an exploration of what the Blanchard hypothesis implier for interest rate and current account effects of fiscal policy in a market clearing full employment model). In that case (27) becomes:

$$
\tilde{G}=P G+\delta_{g} p g=T+\delta_{g} t>T+\delta t
$$

Thus an expenditure plan adequately covered by current and future taxation using public sector discount rates will imply a net financing gap when evaluated at private sector discount rates:

$$
\tilde{G}-T-\delta_{g} t=0 \Rightarrow \tilde{G}-T-\delta t>0
$$

\section{Fiscal Policy under Keynesian Unemployment}

The benchmark case of equal private and public sector discount rates $\left(\delta=\delta_{g}\right)$ is straightforward. Since capital markets are perfect, a shift of taxation towards the future $\left(\mathrm{dt}=-\delta^{-1} \mathrm{dT}>0\right)$ does not affect pri-ate wealth nor therefore private expenditure, as can be seen from (21). When $\delta_{g}=\delta$, only the discounted value of taxes matters, not their time pattern. There is no effect therefore on unemployment, current account or investment. 
Similar results obtain for a deficit financed increase in government expenditure; we can see from (19) that $\mathrm{dX} / \mathrm{dG}=1$ as a first round effect; but since $\mathrm{d} \tilde{\mathrm{T}}=\mathrm{PdX}$, nothing happens to private wealth and expenditure and no multiplier effects occur. Accordingly, private investment and the current account do not change either. Clearly Keynesian disequilibrium and wage-price rigidities are not sufficient for a multiplier larger than one.

Private and social discount rate differences will change all this, however. The discount factor wedge implies that an increase in government expenditure finauced by taxes tomorrow (i.e. a bond issue today) will not be considered neutral by the private sector; the government budget constraint implies that

$$
\operatorname{PdG}=\delta_{g} \cdot d t
$$

so

$$
\begin{aligned}
P d G-d \tilde{T} & =P d G-\delta d t \\
& =\left\{\delta_{g}-\delta\right\} d t>0
\end{aligned}
$$

Total differentiation of the Keynesian system (21)-(23) yields:

$$
E_{U} \frac{d U}{d G}=\frac{\tilde{\Delta}}{\Delta \delta_{g}}\left(\delta_{g}-\delta\right)>0
$$

$\Delta, \tilde{\Delta}>0$; Analytical expressions for $\tilde{\Delta}$ and $\Delta$ are 1 isted in the Appendix. (31) establishes that a temporary bond financed expansion in government expenditure will unambiguously increase private welfare in Keynesian unemployment if $\delta_{g}>\delta$. It is straightforward to show that a current-tax financed temporary fiscal expansion would not do that. 
The impact welfare effect directly due to $(30)$, but without incorporating the induced welfare gains due to second round multiplier effects in excess of one and induced second period terms of trade effects, equals:

$\left.E_{u} \frac{d U}{P d G}\right|_{I}=\frac{\left(\delta_{g}-\delta\right)}{\delta_{g}}$

Th. is expression will be useful later on.

His ' $r$ private welfare implies higher private expenditure, some of which will fall on tomorrow's home goods, shifting out the GM2 curve (cf. fig. 3); since we art in the K-region, the economy is at a point like A and will in fact stay there, $W / P$ and $P$ remain unchanged. That leads to a second period terms of trade improvement:

$$
\frac{\mathrm{dp}}{\mathrm{PdG}}=\frac{\mathrm{C}_{\mathrm{DE}}}{\Delta \delta_{\mathrm{g}}} \cdot\left(\delta_{\mathrm{g}}-\delta\right)>0
$$

No such future terms of trade improvement will occur if private and social discount rates are the same $\left(\delta=\delta_{g}\right)$.

(32) leads to an interesting result on the investment response to deficit spending under Keynesian unemployment:

$$
\begin{aligned}
\frac{d I}{d G} & =\frac{I^{\prime} \delta}{P} \frac{d p}{d G} \\
& =\frac{I^{\prime} \delta c_{D E}}{\delta \Delta} \cdot\left(\delta_{g}-\delta\right)>0
\end{aligned}
$$

or higher government spending today financed by taxes tomorrow will lead to more rather than less private investment today under temporary Keynesian unemployment conditions. The mechanism is straightforward: expansionary 
21

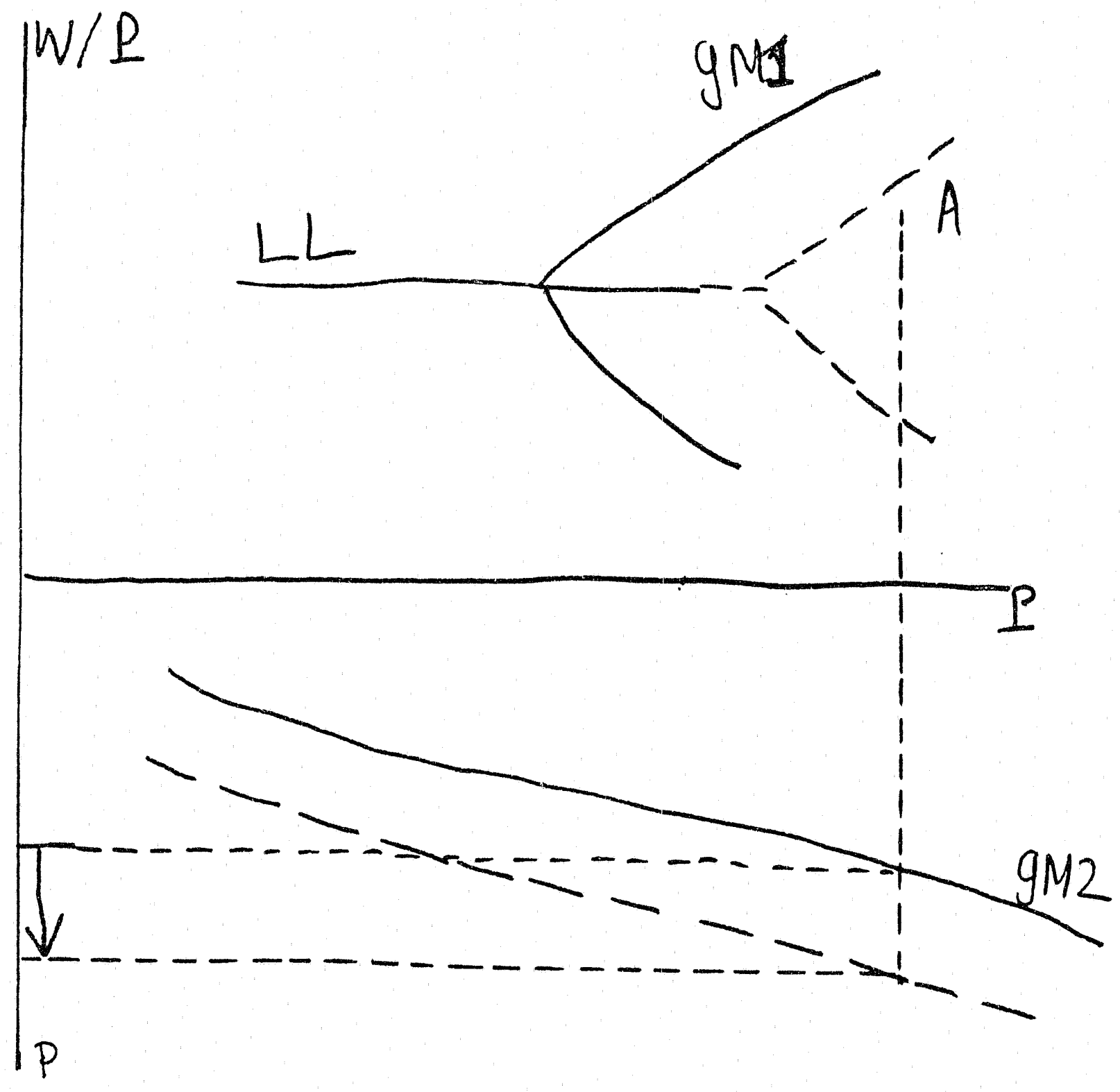

Figure 3: Effects of a Bond Financed Increase in $G$ when $\delta_{g}>\delta$ 
fiscal policy raises welfare (if $\delta_{g}>\delta$ ) and therefore first and second period expenditure. This pushes up the future terms of trade $p$, which in turn increases the value of the marginal product of capital in period 2: the goods produced with that capital now have a higher value. Tobin's "q" goes up and so does private investment. This result is the opposite of the crowding out hypothesis: in fact under temporary Keynesian unemployment there will be crowding in as private investment responds positively to the future terms of trade improvement caused by the fiscal expansion. I/

Moreover part of the increase in private expenditure will fall on today's goods, the equivalent of second and higher rounds of induced spending familiar from standard macro-economic textbooks, so now we do get a multiplier in exeess of one:

$$
\frac{d X}{d G}=1+\frac{\left(r_{p k} I^{\prime} \delta / P-\Sigma_{p p}\right) P c_{D E}}{\Delta \delta_{g}} \cdot\left(\delta_{g}-\delta\right)
$$

(A)

$$
+\frac{\left(\Sigma_{P p}+I^{\prime} \delta / P\right) P c_{D E}}{\Delta \delta_{g}} \cdot\left(\delta_{g}-\delta\right)
$$

$>d G$

1/ A referee points out that imperfect capital mobility or assuming that the domestic economy is large enough to affect the world rate of interest would lead to an increase in real interest rates after a fiscal expansion, which could reverse this result. 
(36) can be rewritten as $1 /$ :

$$
\frac{d X}{d G}=1+\left.\left(r_{p k} I^{\prime} \delta / P-\Sigma_{p p}\right) P C_{D E} E_{u} \frac{d U}{d G}\right|_{I}
$$

(A)

$$
+\left(\Sigma_{P_{P}}+I^{\prime} \delta / P\right) \frac{d p}{d G}
$$

So (the excess over one of) the multiplier can be broken down in two components, one familiar (A), and one unique to the intertemporal framework used here (B). (A) represents induced expenditure effects on output and corresponds to the standard multiplier mechanism; (B) however will only arise in an explicit intertemporal framework. An increase in $p$ increases the Consumption Discount Factor $\delta_{C}(=\delta \pi(p, 1) / \pi(p, 1)$, equal to one over one plus the Consumption Rate of Interest) measuring the terms at which future consumption goods can be traded for current consumption goods. This increase in $\delta_{\mathrm{C}}$ (or, equivalently, $\underline{\text { fall }}$ in the CRI) has a pure substitution effect on private expenditure leading to more expenditure today and less tomorrow adding further terms to the standard expression of the multiplier.

Finally, we turn to the effect of deficit spending on the current account. We have already shown that private first period consumption expenditure will increase. Therefore private saving will not offset the decrease in government savings one for one; second, private investment will increase. So aggregate savings fall and investment increases in period 1. The net effect on the CA (savings minus investment!) is therefore negative.

$1 /$ We use $\frac{d X}{d G}$ etc. as shorthand for $\left.\left\{\frac{\partial X}{\partial G}+\frac{\partial X}{\partial t}\right\}\right|_{d G}=\delta_{g} d t \cdot$ 
A permanent increase in government expenditure $(\mathrm{PdG}=\delta \mathrm{pdg}>0$ ) would add further upward pressure on tomorrow's terms of trade, and so on investment. It would also lead to more private consumption via income effects and substitution effects through the CRI in period one. This would magnify the negative impact on the first period current account deficit. The formal analysis is straightforward and left to the interested reader.

IV. Fiscal Policy Under Classical Unemployment.

Under Classical unemployment the benchmark case $\delta_{g}=\delta$ is of more interest than in the Keynesian case, since increases in first period expenditure cannot be met at unchanged prices. To avoid excessive taxonomy, we will in fact only consider the benchmark case.

Increased first period government expenditure on our goods ( $\mathrm{dG}>0$ ) is, at given wages and prices, inconsistent with first period goods market clearing, since in this regime firms are on their aggregate supply curve. Accordingly the terms of trade will have to inprove to accommodate increased government expenditure, or GMI shifts to the right (fig. 4):

$$
\left.\frac{\mathrm{dP}}{\mathrm{dG}}\right|_{W / P} ^{G M 1}=\frac{\left(1-\mathrm{PC}_{\mathrm{DE}}\right)}{\Sigma_{\mathrm{PP}}-I^{\prime} \delta \mathrm{p} / \mathrm{P}^{2}}>0
$$

However, $\mathrm{G}$ goes up after real wage contracts have been concluded at the beginning of period one. They can be renegotiated at the beginning of the second period, but during period one the real consumption wage $W / \Pi(P, 1)$ is fixed. This means that: 


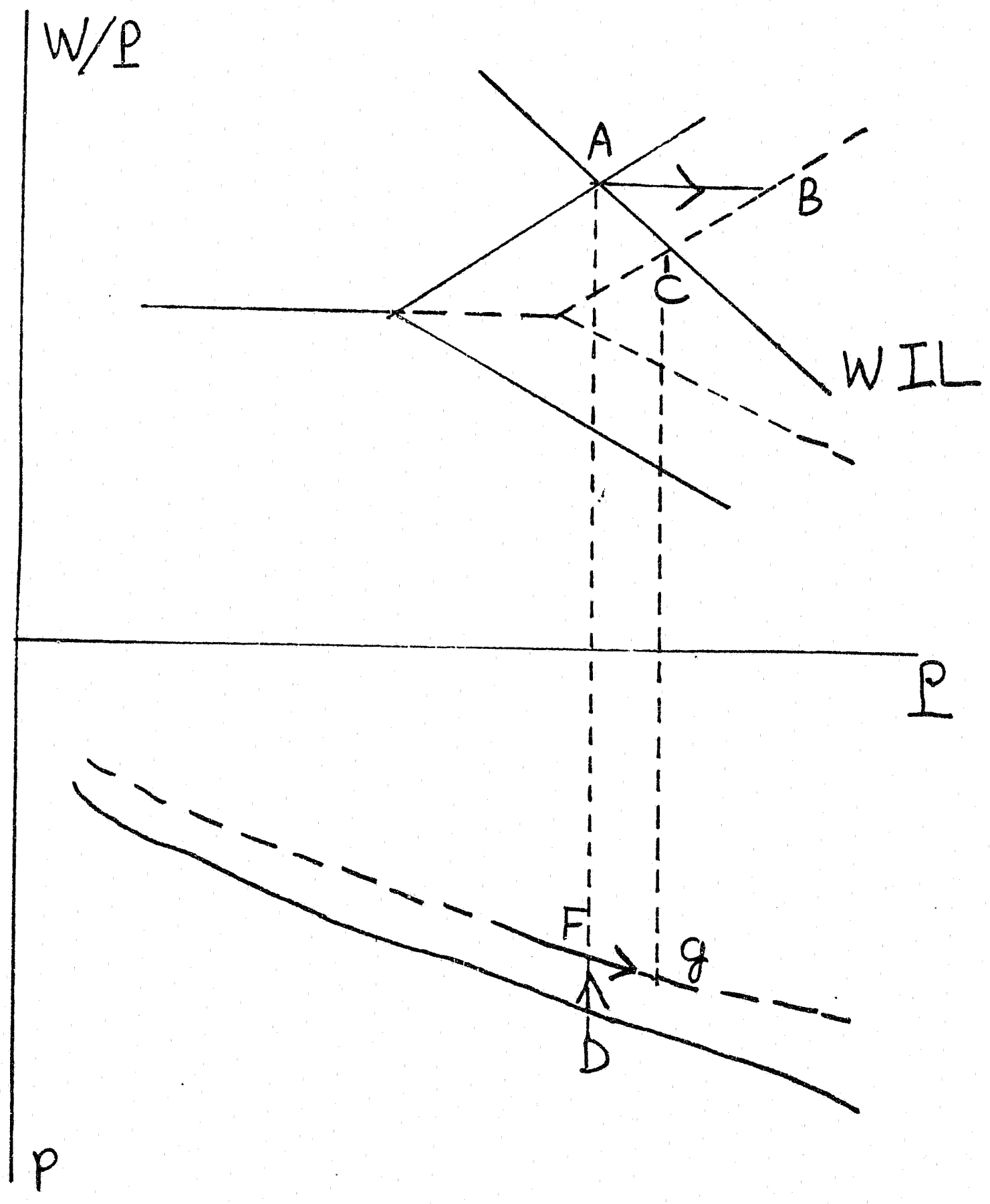

Figure 4: Effects of a Fiscal Expansion Under Classical Unemployment 


$$
\hat{W}-\hat{\Pi}=\hat{W}-\psi \hat{P}=0
$$

or

$$
\hat{W}-\hat{P}=-(1-\Psi) \hat{P}
$$

where $\psi\left(=\mathrm{PI}_{\mathrm{P}} / \mathrm{II}\right)$ is the expenditure share of home goods in first period expenditure. We have labeled (37b) WIL (for Wage Indexation Line) in fig. 4. It passes through A with slope - $(1-\psi)$.

Therefore, after a temporary increase in $\mathrm{G} 1 /$, the starting point $\mathrm{A}$ will now be in a region characterized by excess demand for goods. However upward price flexibility means that this is not sustainable, the real exchange rate will appreciate today (terms of trade $P$ improve, from A to B in fig. 4) until the goods market is back in equilibrium.

However the wage contract stipulates a real consumption wage, indexing is on the CPI. With the real exchange rate appreciation, a fall in the real product wage is possible while maintaining the real consumption wage (cf. $37 b$ ), so instead of going from A to B the economy moves along WIL from A to $\mathrm{C}$, with an appreciated real exchange rate and a lower real product wage. This first result, a real appreciation (terms of trade improvement) in response to an increase in $\mathbf{G}$ is of course not surprising, although it does not take place in standard disequilibrium models (cf. Cuddington and Vinals $(1.986 a, b))$ or in the $\mathrm{K}$-region analyzed in Section 3 .

The real appreciation, combined with a fixed real consumption wage, allows lower real product wages in period 1 . Since output in this regime is constrained by the real product wage and not by effective demand, there will

\footnotetext{
1/ Since we analyze the case where $\delta_{\mathrm{g}}=\delta$ in this section, the financing (bonds or taxes) does not matter. $g$
} 
in fact be some increase in output, although less than in the K-region. In the c-region, the effect of an increase in fiscal expenditure goes partly into prices $(\mathrm{dP}>0)$, partly into quantities. In the $\mathrm{K}$-region it only goes into quantities.

It is of interest to see what determines how the value increase is split up over quantities and prices. Clearly the flatter WIL, the more the effect consists of a real appreciation and the less it consists of a real product wage cut induced output increase. The slope of WIL, (1- $\psi$ ), can be considered a measure of openness of the economy. A very flat line implies $\psi$ is close to one, imports do not play much of a role and therefore any given real appreciation buys only a small decrease in the domestic real product wage. This leads to the interesting result that in the C-region (GMI axis north of $E$ ), more openness means a larger output response and a smaller price response to fiscal expansion. This contrasts with the $\mathrm{K}$-region where a higher import component in expenditure leads to more dissipation of effective demand and smaller output effects.

The effects on the second period terms of trade are ambiguous in the case of a temporary increase in $G$. In that case the GM2 locus shifts back to the zero p-axis (fig. 4), since the impact welfare effect of $G$ on $U$ for given wages and prices is negative; the government's increased use of first period resources implies they are not available for the private sector, with a welfare loss as a result. This spills over into period two, reducing "our" expenditure (ceteris paribus) and therefore causing an ex ante excess supply of home goods. Accordingly their relative price will have to fall to maintain period two goods market equilibrium:

$$
\left.\frac{\mathrm{dP}}{\mathrm{PdG}}\right|_{\mathrm{P}=\overline{\mathrm{P}}}=\frac{{ }_{\mathrm{DE}}}{\Sigma_{\mathrm{PP}}^{\mathrm{c}}}<0
$$


or GM2 shifts down (compare D and F in Fig. 4). $\Sigma_{p p}^{c}$ is defined in the appendix.

On the other hand the real appreciation in period one causes intertemporal substitution effects on consumption, increasing second period demand for our goods. Moreover, since $\mathrm{dP}>0$ implies that the production cost of capital increases, first period investment falls (there is crowding out in the C-region), reducing the supply of period 2 home goods. The latter effect is of course dependent on our assumption that only domestic goods are used for investments. Both factors work toward a real appreciation (a move along GM2 from $F$ to $G$ ). The net effect is ambiguous.

It is shown in the appendix that, even if there is a second period real appreciation $\mathrm{dp}>0$, it will be smaller than the first period one, so that the consumption discount factor $\delta_{c}=1 /(1+C R I)$ and the capital discount factor $\delta_{h}=\delta p / P$ decrease unambiguously. In other words, the Consumption Rate of Interest and the Accounting Rate of Interest go up unambiguously. This leads to a rather surprising possibility of a positive current account response to increased first period fiscal expenditure, even when it is deficit financed (i.e. by bonds rather than taxation).

There are a variety of channels influencing the CA response. The formal expression, where for convenience we look at $\mathrm{CA}_{2}$ rather than $\mathrm{CA}_{1}$, (since $\mathrm{CA}_{1}+\delta \mathrm{CA}_{2}=0$ one can take either one), is:

$$
\begin{aligned}
\mathrm{dCA}_{2} & =d\left(r-E_{\pi} \pi-p g\right) \\
& =r_{k} I^{\prime} \frac{\delta p}{P}\left(\frac{d p}{p}-\frac{d P}{P}\right)
\end{aligned}
$$




$$
\begin{aligned}
& +E_{\pi I I} \frac{I^{2}}{\delta} \cdot \delta_{C}\left(\frac{d p}{p}-\frac{d P}{P}\right) \\
& +E_{p}^{*}\left(C_{I E}-C_{I E}^{*}\right) d p-E_{P}^{*}\left(C_{I I E}-C_{I I E}^{*}\right) d P \\
& +C_{I I E} R_{P W}(1-\psi) W / P \frac{d P}{P} \\
& +C_{I I E} P d G-C_{I E} \delta p d g
\end{aligned}
$$

$\mathrm{C}_{\mathrm{IE}}\left(\mathrm{C}_{\mathrm{IIE}}\right)$ is the marginal propensity to spend in period one (two). Consider the five effects in turn for a temporary increase in government expenditure, $\mathrm{PdG}>0, \mathrm{pdg}=0$. We already saw that in that case $\frac{d P}{P}>\frac{d p}{P}$

Channel (A) indicates that such an increase in the cost of capital in excess of future value of marginal product gains $\left(\frac{d P}{P}>\frac{d p}{p}\right)$ will lead to a fall in first period investment. That in turn caises a fall in second period capital and output and so an improvement in $\mathrm{CA}_{1}$ (decline in $\mathrm{CA}_{2}$ ). Similarly, $\frac{\mathrm{dP}}{\mathrm{P}}>\frac{\mathrm{dP}}{\mathrm{P}}$ has positive pure substitution effects, proportional to $\mathrm{E}_{\pi \Pi}$, on first period savings which improves $\mathrm{CA}_{1}$ (deteriorates $\mathrm{CA}_{2}$ ). This is captured by channel (B). If spending patterns here and abroad are similar $\left(C_{I E}=C_{I E}^{*}\right.$, etc.), terms of trade change induced income effects will not influence the CA; but if we spend more today and less tomorrow than foreigners do $\left(\mathrm{C}_{I E}>\mathrm{C}_{I E}^{*}, \mathrm{C}_{I I E}<\mathrm{C}_{I I E}^{*}\right)$, the higher terms of trade gain today associated with a temporary increase in fiscal expenditure will improve $\mathrm{CA}_{1}$ (deteriorate $\mathrm{CA}_{2}$ ). This is channel $\mathrm{C}$.

Furthermore the first period real appreciation, coupled with real consumption wage indexation, allows a fall in real product wages and an 
increase in first period output. This improves $\mathrm{CA}_{1}$ (deteriorates $\mathrm{CA}_{2}$ ), as captured by channel D.

Finally, the direct effect of increased fiscal expenditure deteriorates the $\mathrm{CA}$, but this effect is moderated because it leads to a fall in welfare which in turn leads to an equal present value drop in private expenditure. For a temporary increase, consumption smoothing explains why this private cut only partially offsets the first period direct current account effects. So this channel (E) leads to a deterioration in $\mathrm{CA}_{1}$ and an improvement in $\mathrm{CA}_{2}$.

Summing up, (A), (B), and (D) are positive influences on the first period CA: (C) is positive if the home country is more impatient (saves less) than the foreign country, while $(E)$ has a negative impact on $\mathrm{CA}_{1}$. A positive first period $\mathrm{CA}$ response to a temporary increase in government expenditure is therefore a distinct possibility.

\section{Conclusion}

We use a 2-period model with optimizing private agents, real wage indexation and downward price rigidity to demonstrate the effects of deficit spending in different employment regimes. The effects of fiscal policy are shown to depend crucially on the type of unemployment (Keynesian or Classical) that prevails.

In a Keynesian unemployment regime, deficit spending increases output and employment. If a plausible assumption about government and private discount rates is introduced, we obtain an interesting result on the private investment response. If private discount rates exceed social discount rates, private consumption expenditure will increase both today and tomorrow in response to the increase in public expenditure, in spite of full anticipation 
of the increased future tax liabilities. Increased future consumption expenditure will lead to a fully anticipated future terms of trade improvement (the price of home goods in terms of foreign goods goes up). Ihis increases the value of the marginal product of capital relative to its (first period) production costs and triggers an increase in private investment in period 1. That is, deficit spending under Keynesian unemployment will lead to crowding in rather than crowding out. Similarly, the increase in private consumption expenditure today coupled with higher government deficits and increased private investment lead to an unambiguously negative link between deficit spending and the current account in this unemployment regime.

The effects of fiscal policy are very different when unemployment is caused by real wages in excess of their market clearing level, leading to low output and employment because of insufficient profitability. Assuming output prices are flexible upwards, a temporary increase in government expenditure in this classical unemployment regime leads to larger terms of trade improvements today than tomorrow. As a result both income and substitution effects lead to a CA improvement. Investment will decline ("crowding out"), furthez improving the current account. The direct (i.e. for given wages and prices) impact of increased first-period government expenditure tends to at least partially offset these surprising positive effects on the CA; the net effect is ambiguous. It is of interest however to note at least the possibility of a first period $\mathrm{CA}$ improvement in response to a temporary increase in government expenditure under classical unemployment.

Finally we show that the more open the economy is, cald larger is the output response and the smaller the price response to a fiscal expansion in the presence of classical unemployment. This contrasts with the Keynesian 
unemployment regime, where a higher import component in expenditure leads to more dissipation of effective demand and smaller output effects. 


\section{REFERENCES}

Alogoskoufis, G. and C. Pissarides (1983), "A Test of Price Sluggishness in a simple Rational Expectations Model: Britain 1950-1980", Economic Journa1, vo1. 93, pp. 616-628.

Barro, R. (1974), "Are Government Bonds Net Wealth?", Journal of Political Economy, vo1. 82, pp. 1095-1117.

Barro, R. and H. Grossman (1976), Money, Employment and Inflation, Cambridge University Press.

Benassy, J. P. (1975), "Neo-Keynesian Disequilibrium Theory in a Monetary Economy," Review of Economic Studies, vo1. 42, pp. 503-524.

Blanchard, 0, (1985), "Debt, Deficits and Finite Horizons," Journal of Political Economy, vol. 93, pp. 223-247.

Bruno, M. (1982), "Macroeconomic Adjustment under Wage-Price Rigidity," in J. hagwati (ed.), Import Competition and Response, University of Chicago Press for the NRER.

Cuddington, J. and J. Vinals (1986a), "Budget Deficits and the Current Account in Classical Unemployment," Economic Journal, vol. 96, pp. 101-119.

(1986b), "Budget Deficits and the Current Account: An Intertemporal disequilibrium approach. Journal of International Economics, vo1. 21, pp. 1-24.

Dixit, A. and V. Norman (1980), Theory of International Trade, Cambridge University Press.

Fischer, S. (1977), "Long Term Contracts, Rational Expectations, and the Optimal Money Supply Rule", Journal of Political Economy, vol. 85, pp. 191-205.

Frenke1, J. and A. Razin (1985a), "Government Spending, Debt and International Economic Interdependence," Economic Journal, vol. 95, pp. 619-636.

Frenke1, J. and A. Razin (1985b), "Fiscal Expenditures and International Economic Interdependence," in International Economic Policy Coordination, eds. W. Buiter and R. Marston, Cambridge U.P.

Gray, J. (1978), "On Indexation and Contract Length", Journal of Political Economy, vol. 86, pp. 1-18.

Green, J. and J. J. Laffont (1981), "Disequilibrium Dynamics with Inventories and Anticipatory Price Setting", European Econonic Review, vol. 16, pp. 199-221.

Haavelmo, T. (1945), "Multiplier Effects of a Balanced Budget", Econometrica, vo1. 13, pp. 311-318. 
Hicks, J. R. (1939), "Mr. Keynes and the "Classics": A Suggested Interpretation," Econometrica, vol. 7, pp. 147-159.

Keynes, J. M. (1936), The General Theory of Employment, Interest and Money, Macmillan, London.

Malinvaud, E. (1977), The Theory of Unemployment Reconsidered, Oxford, Basic Blackivel1.

Neary, J. P. (1980), "Non-Traded Goods and the Balance of Trade in a NeoKeynesian Temporary Equilibrium," Quarterly Journal of Economics, vo1. 95, pp. 403-429.

Neary, J. P. and J. Stiglitz (1983), "Towards a Reconstruction of Keynesian Economics: Expectations and Constrained Equilibria," Quarterly Journal of Economics, vo1. 98, (Supp1.), pp. 199-228.

Reagan, P. (1982), "Inventory and Price Behaviour," Review of Economic Studies, vol. 49, pp. 137-142.

Reagan, P. and M. Weitzman (1982), "Asymmetries in Price and Quantity Adjustments by the Competitive Firm," Journal of Economic Theory, vol. 27 , pp. 410-421.

Syensson, L. and A. Razin (1983), "The Terms of Trade. Spending and the Current Account: the Harberger-Laursen-Metzler Effect", Journal of Political Economy, vol. 91, pp. 97-125.

van Wijnbergen, S. (1984), "The Dutch Disease: A Disease After Al1?", Economic Journal, vol. 94, pp. 41-56.

van Wijnbergen, S. (1985), "Oil Price Shocks, Private investment, Employment and the Current Account: an Intertemporal Disequilibrium Analysis," Review of Economic Studies, vo1. 52, pp. 627-645.

van Wijnbergen, S. (1986), "On Fiscal Deficits, the Real Exchange Rate and the World Rate of Interest", European Economic Review, vol. 30, pp. 10131023.

Yaari, M. (1965), "Uncertain Lifetime, Life Insurance and the Theory of the Consumer", Review of Economic Studies, vol. 32, pp. 137-150. 
I. The Equilibrium Model

1. Model Equations

Budget Constraints; -Private Sector:

$\mathrm{R}+\delta \mathrm{r}-\tilde{\mathrm{T}}-\mathrm{P} I=\mathrm{E} ; \mathrm{R}^{*}+\delta \mathrm{r}^{*}=\mathrm{E}^{*} \quad$ E.I

-Government:

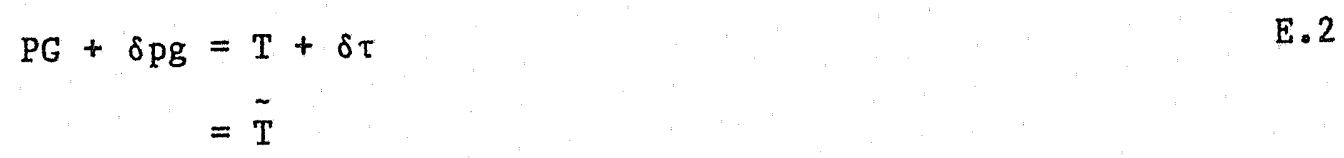

Goods Markets; -period 1(GM1)

$R_{p}=E_{p}+E_{P}^{*}+G+I$

E. 3

-period 2(GM2)

$r_{p}=E_{p}+E_{p}^{*}+g$

E.4

where investment is derived from:

$\delta r_{k}(K+I)=P$

E.5 
2. The way the model works

Welfare

$\left(R_{P}-E_{P}-I\right)-\left(P-\delta r_{k}\right) I_{P} d P$

$+\left(r_{p}-E_{p}+\left(\delta r_{k}-p\right) I_{p}\right) d p-d T-\delta d t$

$=\mathrm{E}_{\mathrm{u}} \mathrm{dU}$

or, using E.5 and evaluating around $\mathrm{G}=\mathrm{g}=0$ :

$E_{P}^{*} d P+E_{p}^{*} \delta d P-d T-\delta d t=E_{u} d U$

For foreigners, $\mathrm{R}_{\mathrm{P}}^{*}=r_{\mathrm{p}}^{*}=0$, hence

$-E_{P}^{*} d P-E_{P}^{*} \delta d p=E_{u}^{*} d U^{*}$

Substitute this in E.3-4 to get

$$
\begin{gathered}
\left(E_{P P}+E_{P P}^{*}+\left(C_{D E}-C_{D E}^{*}\right) E_{P}^{*}-I^{\prime} \frac{\delta p}{P^{2}}\right) d P \\
+d G-C_{D E}(d T+\delta d t) \\
+\left(E_{P p}+E_{P p}^{*}+\left(C_{D E}-C_{D E}\right) E_{p}^{*}+I^{\prime} \delta / P\right) d p \\
=0
\end{gathered}
$$

using $R_{P P}=\frac{\partial X(K, L)}{\partial P}=0$ and $E_{P U} E_{U}^{-1}=C_{D E}$ 
Similarly GM2:

$$
\begin{aligned}
& \left(E_{p P}+E_{p P}^{*}+\left(c_{D E}-c_{D E}^{*}\right) E_{P}^{*}+r_{p k} \delta p / P^{2}\right) d P \\
& +\left(E_{p p}+E_{p p}^{*}+\left(c_{D E}-c_{D E}^{*}\right) E_{p}^{*}-r_{p k} I^{\prime} \delta / P\right) d p \\
& +d g-c_{D E}(d T+\delta d t)=0
\end{aligned}
$$

II. Fiscal Expenditure Effects under Keynesian Unemployment

1. The Model

$$
\begin{aligned}
& P X+\delta r-P I-\tilde{T}=E, R^{*}+\delta r^{*}=E^{*} \\
& X=E_{P}+E_{P}^{*}+I+G \\
& r_{P}=E_{p}+E_{p}^{*}+g
\end{aligned}
$$

2. Differentiate. Policy Experiment $\mathrm{PdG}=\delta \mathrm{gdt}$.

$$
\begin{aligned}
& {\left[\begin{array}{cc}
1-\mathrm{PC}_{\mathrm{DE}} & -\left(\Sigma_{\mathrm{Pp}}+\mathrm{I}^{\prime} \delta / \mathrm{P}\right) \\
-\mathrm{C}_{\mathrm{DE}} \mathrm{P} & -\left(\Sigma_{\mathrm{pp}}-\mathrm{r}_{\mathrm{pk}} I^{\prime} \delta / \mathrm{P}\right)
\end{array} \mid \begin{array}{l}
\mathrm{dX} \\
\mathrm{dp}
\end{array}=\right.} \\
& {\left[\begin{array}{c}
d G-C_{D E}(d T+\delta d t) \\
\cdot d g-c_{D E}(d T+\delta d t)
\end{array}\right]}
\end{aligned}
$$




$$
\Delta=-\left(1-\mathrm{PC}_{\mathrm{DE}}\right)\left(\Sigma_{\mathrm{pp}}-\mathrm{r}_{\mathrm{pk}} I^{\prime} \delta / \mathrm{P}\right)+c_{\mathrm{DE}} \mathrm{P}\left(\Sigma_{\mathrm{Pp}}+I^{\prime} \delta / \mathrm{P}\right)>0
$$

Cramer's Rule yields

$$
\begin{aligned}
\frac{\mathrm{dX}}{\mathrm{d} G}=1 & +\frac{\left({ }_{\mathrm{pk}} \mathrm{I}^{\prime} \delta / \mathrm{P}-\Sigma_{\mathrm{pP}}\right)}{\Delta} \frac{\mathrm{PC}_{\mathrm{DE}}}{\delta_{\mathrm{g}}}\left(\delta_{g}-\delta\right) \\
& +\frac{\left(\Sigma_{\mathrm{Pp}}+I^{\prime} \delta / P\right)}{\Delta} \frac{P C_{D E}}{\delta_{g}} \cdot\left(\delta_{g}-\delta\right)
\end{aligned}
$$

III. Fiscal Expenditure Effects in Classical Unemployment

\section{The Model}

Goods market, period one:

$R_{P}(P, W / P)=E_{P}+E_{P}^{*}+I(\delta p / P)+G$

Goods market, period two:

$r_{p}(p, K+I)=E_{p}+E_{p}^{*}+g$

Intertemporal budget constraint

$$
R+\delta r-P I-\tilde{T}=E(\Pi, \delta \pi, U)
$$

Wage indexation

$W / \Pi(P, 1)=T$ 
39

2. Solution

- Differentiate A.1-4, substitute out U, via A.3-4. This results in:

$$
\left[\begin{array}{cc}
\Sigma_{\mathrm{pp}}^{\mathrm{c}} & -\Sigma_{\mathrm{pp}}^{\mathrm{c}} \\
-\Sigma_{\mathrm{pp}}^{\mathrm{c}} & -\Sigma_{\mathrm{pp}}^{\mathrm{c}}
\end{array}\right]_{-}^{\mathrm{dP}}=\left[\begin{array}{l}
\left(1-\mathrm{PC}_{\mathrm{DE}}\right) \mathrm{dG}-\delta \mathrm{pC} \mathrm{DE}_{\mathrm{dg}} \\
\left.-\mathrm{c}_{\mathrm{DE}}^{\mathrm{PdG}+(1-\delta \mathrm{pc}} \mathrm{DE}\right) \mathrm{dg}
\end{array}\right]
$$

A. 5

where

$$
\begin{aligned}
\Sigma_{p p}^{c} & =E_{p p}+E_{p p}^{*}-R_{p p}-I^{\prime} \delta p / p^{2} \\
& +E_{p}^{*}\left(C_{D E}-C_{D E}^{*}\right)+R_{P \tilde{W}}(1-\psi)\left(1-P C_{D E}\right) W / P^{2}<0 \\
\Sigma_{p p}^{c} & =E_{p p}+E_{p p}^{*}-r_{p p}-I^{\prime} \delta p / P
\end{aligned}
$$$$
+E_{p}^{*} \delta\left(c_{D E}-c_{D E}^{*}\right)<0
$$

$$
\begin{aligned}
\Sigma_{p p}^{c} & =E_{p P}+E_{p p}^{*}+r_{p k} I^{\prime} \delta p / p^{2} \\
& +E_{p}^{*} \delta\left(c_{D E}-c_{D E}^{*}\right)-(1-\psi) \dot{R}_{P \tilde{W}} c_{D E} W / P^{2}>0 \\
\Sigma_{p p}^{c} & =E_{p p}+E_{p p}^{*}+I^{\prime} \delta / P+E_{p}^{*} \delta\left(C_{D E}-C_{D E}^{*}\right)>0
\end{aligned}
$$

Note that symmetric expenditure patterns across countries and, more importantly, time periods, imply 


$$
\begin{aligned}
& \Sigma_{\mathrm{pp}}^{\mathrm{c}}<\Sigma_{\mathrm{pp}}^{\mathrm{c}}, \Sigma_{\mathrm{pp}}^{\mathrm{c}}>\Sigma_{\mathrm{pp}}^{\mathrm{c}} \\
& \Sigma_{\mathrm{pp}}+\Sigma_{\mathrm{pp}}<0, \Sigma_{\mathrm{pp}}+\Sigma_{\mathrm{pp}}<0
\end{aligned}
$$

These symmetry assumptions (i.e. $\Pi_{P} P / \pi=\pi_{p} p / \pi$ etc.) are made throughout.

3. Terms of Trade Effects of a Transitory Increase in Government Expenditure $d \mathrm{G}>0, \mathrm{dg}=0$.

$$
\begin{aligned}
& \frac{\mathrm{d} P}{\mathrm{dG}}=\frac{1}{\Delta}\left\{-\Sigma_{\mathrm{pp}}^{\mathrm{c}}\left(1-\mathrm{PC} \mathrm{DE}_{\mathrm{DE}}\right)-\Sigma_{\mathrm{pp}}^{\mathrm{c}}\left(1-\delta \mathrm{pc} \mathrm{DE}_{\mathrm{DE}}\right)\right\}>0 \\
& \frac{\mathrm{d} \mathrm{p}}{\mathrm{dG}}=\frac{1}{\Delta}\left\{\Sigma_{\mathrm{pP}}^{\mathrm{c}}\left(1-\mathrm{PC} \mathrm{DE}_{\mathrm{DE}}\right)+\Sigma_{\mathrm{pp}}^{\mathrm{c}} \mathrm{C}_{\mathrm{DE}} \mathrm{P}\right\} \stackrel{>}{<} 0
\end{aligned}
$$

The inequalities in A.7 and A.8 can be obtained by applying A.6.

$$
\begin{aligned}
& \Delta=\Sigma_{\mathrm{PP}}^{\mathrm{c}} \Sigma_{\mathrm{pp}}^{\mathrm{c}}-\Sigma_{\mathrm{pP}}^{\mathrm{c}} \Sigma_{\mathrm{Pp}}^{\mathrm{c}}>0 \\
& \text { a1so } \frac{d p}{d G}-\frac{d p}{d G}=\frac{1}{\Delta}\left\{-\Sigma_{p P}^{c}\left(1-P C_{D E}\right)-\Sigma_{p p}^{c} P c_{D E}\right. \\
& \left.-\Sigma_{p P}^{c}\left(1-P C_{D E}\right)-\Sigma_{P P}^{c} c_{D E} P\right\}
\end{aligned}
$$

It is straightforward to see that this expression is positive - (note that a1l terms involving $\mathrm{R}_{\mathrm{P} \tilde{\mathrm{W}}}$ cancel out). 
4. Terms of Trade Effects of a Permanent Increase in Government Expenditure PdG $=\delta p d g>0$.

Define $\frac{\mathrm{dP}}{\mathrm{PdG}}=\left.\left(\frac{\mathrm{dP}}{\mathrm{PdG}}+\frac{\mathrm{dP}}{\delta \mathrm{pdg}}\right)\right|_{\mathrm{PdG}}=\mathrm{p} \delta \mathrm{dg}$ etc.

$\frac{\mathrm{dP}}{\mathrm{dG}}=\frac{1}{\Delta}\left\{-\Sigma_{\mathrm{pp}}^{\mathrm{c}}\left(1-\mathrm{PC}_{\mathrm{DE}}\right)+\Sigma_{\mathrm{PP}}^{\mathrm{c}}(1-\delta \mathrm{pc} \mathrm{DE})\right.$

$\left.+\Sigma_{\mathrm{PP}}^{\mathrm{c}} \mathrm{PC} \mathrm{DE}_{\mathrm{PE}}-\Sigma_{\mathrm{Pp}}^{\mathrm{c}} \delta \mathrm{pc}_{\mathrm{DE}}\right\}$

$\frac{\mathrm{dp}}{\mathrm{dG}}=\frac{1}{\Delta}\left\{-\Sigma_{\mathrm{pp}}^{\mathrm{c}}\left(1-\delta p c_{\mathrm{DE}}\right)+\Sigma_{\mathrm{pP}}^{\mathrm{c}}\left(1-\mathrm{PC} \mathrm{DE}_{\mathrm{DE}}\right)\right.$

$\left.+\Sigma_{\mathrm{pP}}^{\mathrm{c}} \delta \mathrm{pc}{ }_{\mathrm{DE}}-\Sigma_{\mathrm{pP}}^{\mathrm{c}} \mathrm{PC}_{\mathrm{DE}}\right\}$

Since symmetry over time implies $\mathrm{PC}_{\mathrm{DE}}=\delta \mathrm{pc}_{\mathrm{DE}}$,

$1-\mathrm{PC}_{\mathrm{DE}}-\mathrm{PC}_{\mathrm{DE}}=1-\delta \mathrm{PC}{ }_{\mathrm{DE}}-\delta \mathrm{pC_{ \textrm {DE } }}>0$; therefore

$\frac{\mathrm{dP}}{\mathrm{dG}}, \frac{\mathrm{dp}}{\mathrm{dG}}>0$

Finally straightforward application of A.6 to A.9-10 shows that

$\frac{d P}{d G}<\frac{d p}{d G}$ 
Some Recent DRD Discussion Papers

237. Tax Reforms, Welfare, and Effective Tax Rates, by W. R. Thirsk.

238. Lessons from Value-Added Taxation for Developing Countries, by M. Gillis, C. Shoup and G.P. Sicat.

239. Adjustments to Policy Changes: The Case of Korea, 1960-1985, by R. Richardson and B.W. Kim.

240. Adopting a Value-Added Tax in a Developing Country, by. G.P. Sicat.

241. External Shocks and Policy Reforms in the Southern Tone: A Reassessment, by $\mathrm{V}$. Corbo and J. de Melo.

242. Adjustment with a Fixed Exchange Rate: Cameroon, Cote d'Ivoire and Senegal, by S. Devarajan and J. de Melo.

243. Savings, Commodity Market Rationing and the Real Rate of Interest in China, by. A. Feltenstein, D. Lebow, and S. van Wijnbergen.

244. Labor Markets in Sudan: Their Structure and Implications for Macroeconomic Adjustment, by P.R. Fallon.

245. The VAT and Services, by J.A. Kay and E.H. Davis.

246. Problems in Administering a Value-Added Tax in Developing Countries: an Overview, by M. Casanegra de Jantscher.

247. Value-Added Tax at the State Level, by S. Poddar.

248. The Importance of Trade for Developing Countries, by B. Balassa.

249. The Interaction of Domestic Distortions with Development Strategies, by B. Balassa.

250. Economic Incentives and Agricultural Exports in Developing Countries, by B. Balassa.

251. Lessons from the Southern Cone Policy Reforms, by V. Corbo and J. de Me1o.

252. On the Progressivity of Commodity Taxation, by S. Yitzhaki.

253. A Full Employment Economy and its Responses to External Shocks: The Labor Market in Egypt from World War II, by B. Hansen.

254. Next Steps in the Hungarian Economic Reform, by B. Balassa.

255. On the Progressivity of Commodity Taxation, by S. Yitzhaki. 